\title{
RHEUMATOID ARTHRITIS AND GRANULOMATOSIS WITH POLYANGIITIS (WEGENER'S GRANULOMATOSIS): A RARE ASSOCIATION
}

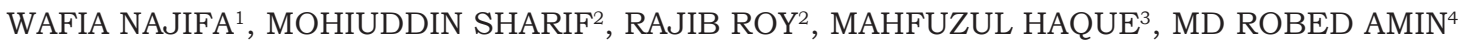

\begin{abstract}
:
The presentation of Rheumatoid arthritis (RA) combined with a second rheumatological disorder that is, different $R A$ overlap syndromes are frequently encountered in clinical practice. But RA-vasculitis overlaps are relatively rare. This paper presents a case of Rheumatoid arthritis and Granulomatosis with polyangiitis (Wegener granulomatosis) overlap syndrome which is first of its kind reported from Bangladesh.
\end{abstract}

Keywords: Rheumatoid arthritis, Granulomatosis with polyangiitis (Wegener's granulomatosis), Anti neutrophil cytoplasmic antibody, cANCA, pANCA, ANCA associated vasculitis (AAV).

Received: 05 March 2020

Accepted: 12 June 2020

DOI: https://doi.org/10.3329/bjm.v31i2.48542

\section{Introduction:}

Rheumatoid arthritis and Granulomatosis with polyangiitis (GPA) are both immunolologically mediated diseases involving multiple systems. However, they are unrelated separate entities. Their distinction lies in the underlying pathology and mode of presentation.

In RA patients, modification of peptides by citrullination occurs in particular sites like synovium. This renders them immunogenic and auto-antibodies (anti-ccp, rheumatoid factor) are generated against them leading to inflammation. 1 This happens in genetically susceptible individuals with certain variants in MHC and non MHC associated genes when they are exposed to environmental triggers like infection and smoking. Symmetrical polyarthritis is the dominant presentation of RA. Extra-articular or multisystem involvement including vasculitic features appear as complications in long standing untreated cases. ${ }^{2}$

Granulomatosis with polyangiitis (Wegener's) is a primary small vessel vasculitis syndrome associated with cytoplasmic anti neutrophil cytoplasmic antibody (cANCA) in more than $90 \%$ of cases. Necrotising inflammation occurs in the endothelial wall of small arteries and veins. The pathological hallmark is intra and extravascular granuloma formation. The cardinal sites are upper (95\%) \& lower (85-90\%) respiratory tracts and glomerulus of kidney (77\%). The typical initial presentation is multisystem involvement with epistaxis, haemoptysis due to cavitary lesion in lung and features of glomerulonephritis. ${ }^{3}$ Besides, there are involvements of skin (46\%), joints (67\%), ocular $(52 \%)$, cardiovascular $(8 \%)$ and nervous $(23 \%)$ systems. ${ }^{4}$ The disease follows an aggressive course and the rate of mortality in severe disease is upto $90 \%$ within 2 years without treatment. 5

\section{Case Summary:}

A 40 year old man who was diabetic and smoker was admitted to Medicine admission unit at $\mathrm{DMCH}$ in January 2019. He was suffering from undiagnosed and inadequately treated rheumatoid arthritis for 5 years, occasional high grade fever with chills and rigor for 1 year, melaena for 6 months and haemoptysis, unprovoked epistaxis with nasal crusting $\&$ respiratory distress for 4 months and $9 \mathrm{~kg}$ weight loss over last 4 months. He had no history of bronchial asthma. He was on anti-TB therapy for 3 months without response. Previous investigations revealed Anti-CCP 41.97U/L (positive), sputum negative for AFB, $5 \mathrm{~mm}$ induration in MT and two cavitary lesions in right mid and lower zones of his chest X-ray (figure-1 a) and CT chest (figure-1b).

1. Honorary Medical Officer, Department of Medicine, Dhaka Medical College and Hospital

2. Indoor Medical Officer, Department of Medicine, Dhaka Medical College and Hospital

3. Assistant Professor of Medicine, Dhaka Medical College

4. Professor of Medicine, Dhaka Medical College

Address of correspondence: Dr. Wafia Najifa, Honorary Medical Officer,Department of Medicine, Dhaka Medical College and Hospital. Email-wafianajifa@hotmail.com

Bangladesh J Medicine 2020; 31 : 114-119 

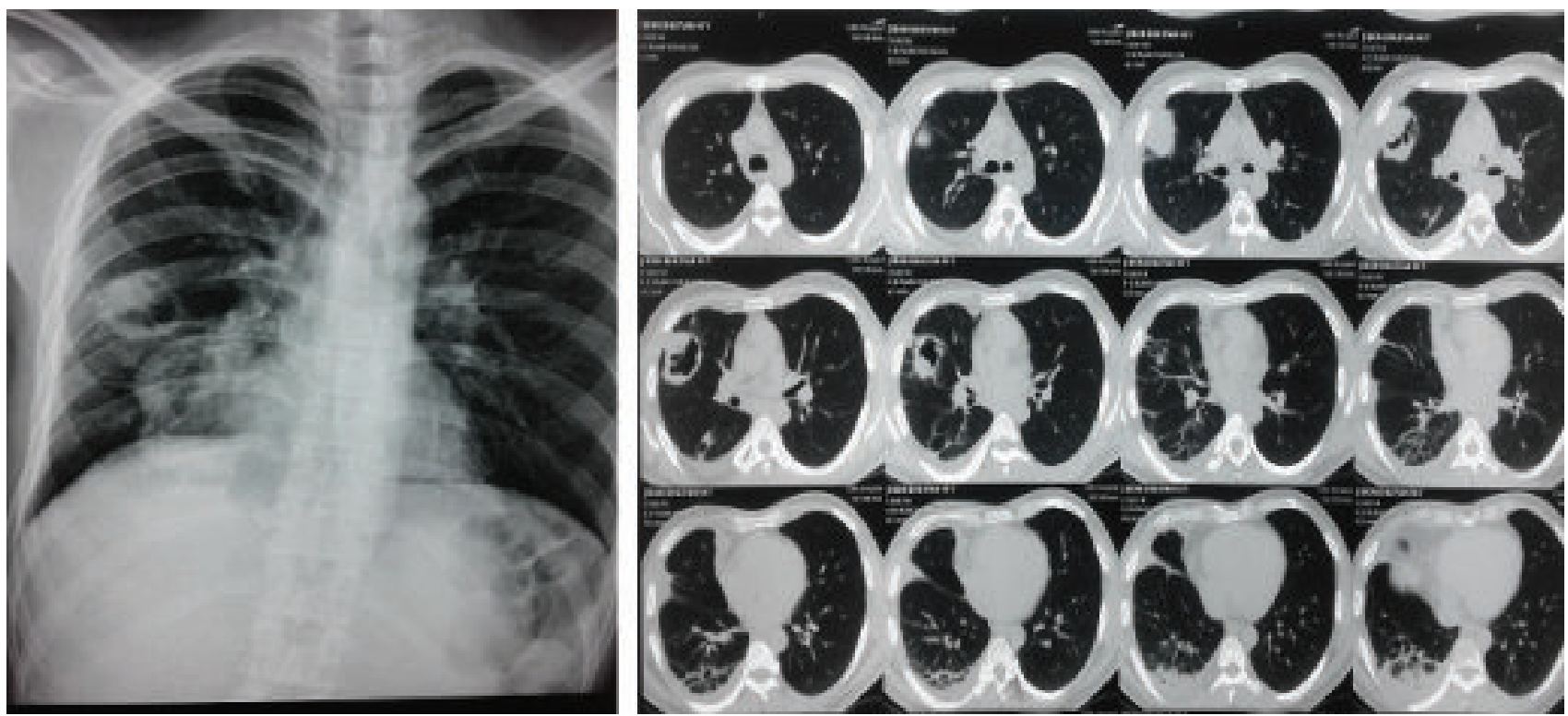

Figure-1 (a\&b): Two cavities in right lung field and also in CT scan of chest

During the course of anti- TB treatment, he developed painful necrotising skin lesions all over the body, in oral cavity \& pharynx, ulcer on dorsum of feet, conjunctivitis, an episode of delirium with fever as well as exacerbations of all pre-existing symptoms. These complications were treated with multiple short courses of both oral and injectable steroid, antibiotic, anti viral, NSAIDs and hydroxychloroquine at different times according to his medical records.

Following admission at $\mathrm{DMCH}$, patient developed oral thrush, bipedal pitting oedema, high coloured urine and ulcer over scrotum and inner aspect of thighs (figure-2). Anti- tubercular drug was stopped and patient was re-evaluated.

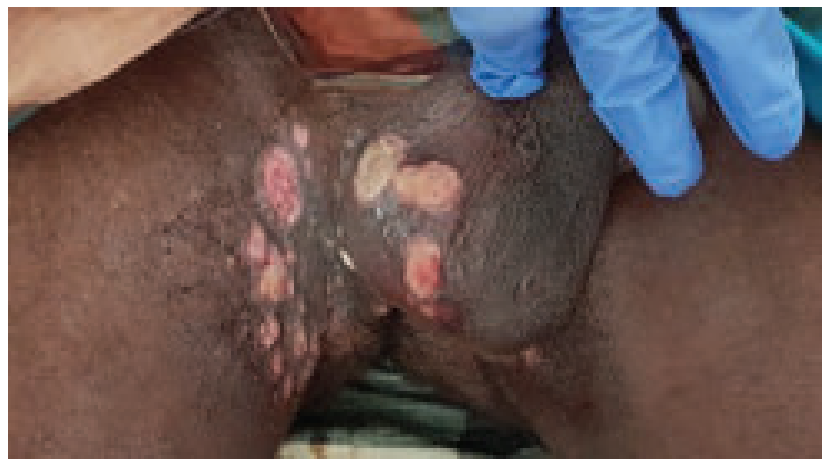

Fig.-2: Ulcers on scrotum and inner thighs

Other significant clinical findings were as follows. Multiple crusts with many healed scars all over the body specially on face, all four limbs and oral cavity, ulcers on dorsum of left foot, temperature $102^{\circ} \mathrm{F}$, pulse $102 \mathrm{bpm}$, BP 120/80 mmHg and body weight $43 \mathrm{~kg}$.
His breath sound was vesicular in both lung fields with mild inspiratory crackles in right $5^{\text {th }}$ to $7^{\text {th }}$ ICS in midscapular line and normal vocal resonance. PIP joints of all fingers of both hands, both wrist, elbow, knee and ankle joints were swollen and tender. Score of EULAR/ACR clinical classification criteria for RA was 10 and DAS 28 score was 7.95 .

Further investigations were done. Reports showed haemoglobin $11.5 \mathrm{~g} / \mathrm{dL}$, WBC 12 480/il, neutrophil $77.8 \%$, lymphocyte $18.3 \%$, eosiniphil $0.3 \%$, platelet 7 50 00, ESR $110 \mathrm{~mm}$ in $1^{\text {st }}$ hour, CRP $180 \mathrm{mg} / \mathrm{L}$, s. creatinine $0.8 \mathrm{gm} / \mathrm{dL}$, anti-CCP $310 \mathrm{U} / \mathrm{mL}$, RF 225 $\mathrm{IU} / \mathrm{mL}$, cANCA $14.5 \mathrm{U} / \mathrm{mL}$ and pANCA $3.10 \mathrm{U} / \mathrm{mL}$. MTB was not detected in sputum for gene Xpert but sputum culture revealed growth of $E$. coli that was sensitive to Meropenem, Tazobactum-Piperacillin, Gentamicin, Cotrim and Colistin. No fungal hyphae was found in $\mathrm{KOH}$ preparation of sputum. Sputum culture for fungus was negative. Urine $\mathrm{R} / \mathrm{E}$ revealed albumin +++ and plenty RBC of which $25 \%$ were dysmorphic on phase contrast microscopy. 24 hours Urinary volume and 24 hours urinary total protein were $1200 \mathrm{~mL}$ and 3.48gm respectively.

Though renal and skin biopsies were planned but considering the extreme debilitating condition of the patient, they were postponed. Instead, a working diagnosis of "Granulomatosis with polyangiitis (Wegener's granulomatosis) with Rheumatoid arthritis Overlap Syndrome with Diabetes Mellitus" was made and was managed accordingly. 
Patient was treated with pulse i/v Methylprednisolone $1 \mathrm{gm} /$ day for 5 days followed by oral Prednisolone 60 $\mathrm{mg} /$ day and pulse i/v Cyclophosphamide $15 \mathrm{mg} / \mathrm{kg}$ single dose. In addition, injection Meropenem, oral Linezolid and Fluconazole were given for infection. Diabetes was controlled with premixed insulin.

Skin and renal biopsy were done once the patient became stable. Renal biopsy revealed pauci-immune focal crescentic ANCA associated glomerulonephritis (figure-3). Sections showed renal cortex and medulla containing 22 glomeruli of which 2 were globally sclerosed and 3 had segmental sclerosis. Crescent formation was noted in 5 glomeruli of which 3 were cellular crescents and 2 were fibrocellular crescents. Most of the crescents presented necrotising features and a few had ruptured bowman capsule. The uninvolved glomeruli had normal messangial cellularity and normal thickness of glomerular basement membrane. There was no endocapillary proliferation. Silver methanamine stain revealed no crater or spike formation. Interstitial fibrosis and tubular atrophy occupied $5 \%$ cortical area. Focal lymphocytic infiltration was present in the interstitium. Tubules had mild acute tubular injury. Features of vasculitis were present in small vessels but arterioles were unremarkable. While skin biopsy reported ulcer in epidermis and mild infiltration of acute and chronic inflammatory cells in and around blood vessels with increased deposition of collagen in upper dermis (figure-4). No immune deposit was found in either renal or skin biopsies under direct immunofluorescence microscopy.

Patient was discharged after improvement of general wellbeing. His next treatment plan included administration of total 18 cycles of injection Cyclophosphamide $15 \mathrm{mg} / \mathrm{kg} /$ dose (monthly for 6 cycles, 3 monthly for 6 cycles then 6 monthly for 6 cycles) and tapering of Prednisolone by $2.5 \mathrm{mg}$ per week after 2 months.

Within the course of a month after starting treatment, fever and joint pain subsided, bleeding manifestations stopped, ulcers healed, lung cavities almost resolved (figure-8) and 24 hours urinary total protein decreased to $0.59 \mathrm{gm}$ where 24 hour urinary volume was 3950 $\mathrm{mL}$.

However, patient developed atrophic rhinitis and epiphora due to bilateral dacryocystitis 4 months after starting treatment. Atrophic rhinitis was managed with regular nasal irrigation with $25 \%$ glucose in glycerine solution and another solution containing one part sodium bicarbonate, one part sodium biborate and two part sodium chloride. Besides, he developed Mooren's ulcer in the cornea of his right eye on $8^{\text {th }}$ month of starting immunosuppressants. This was treated with topical steroid. Moreover, a new $\left(3^{\text {rd }}\right)$ cavitary lesion was detected in the mid zone of left lung field of his chest X-ray during follow up visit on $9^{\text {th }}$ month (figure5). All these new features started appearing when the tapering oral prednisolone dose reached around 25 mg. As a result, the dose of oral prednisolone was reescalated to $60 \mathrm{mg}$ along with the pre-scheduled cyclophosphamide. Prednisolone was tapered by 2.5 mg per week after 2 months and Azathioprine $50 \mathrm{mg}$ was started when daily dose of prednisolone reached $20 \mathrm{mg}$. CT scan of chest done three months later showed resolution of all 3 cavities (figure-6).
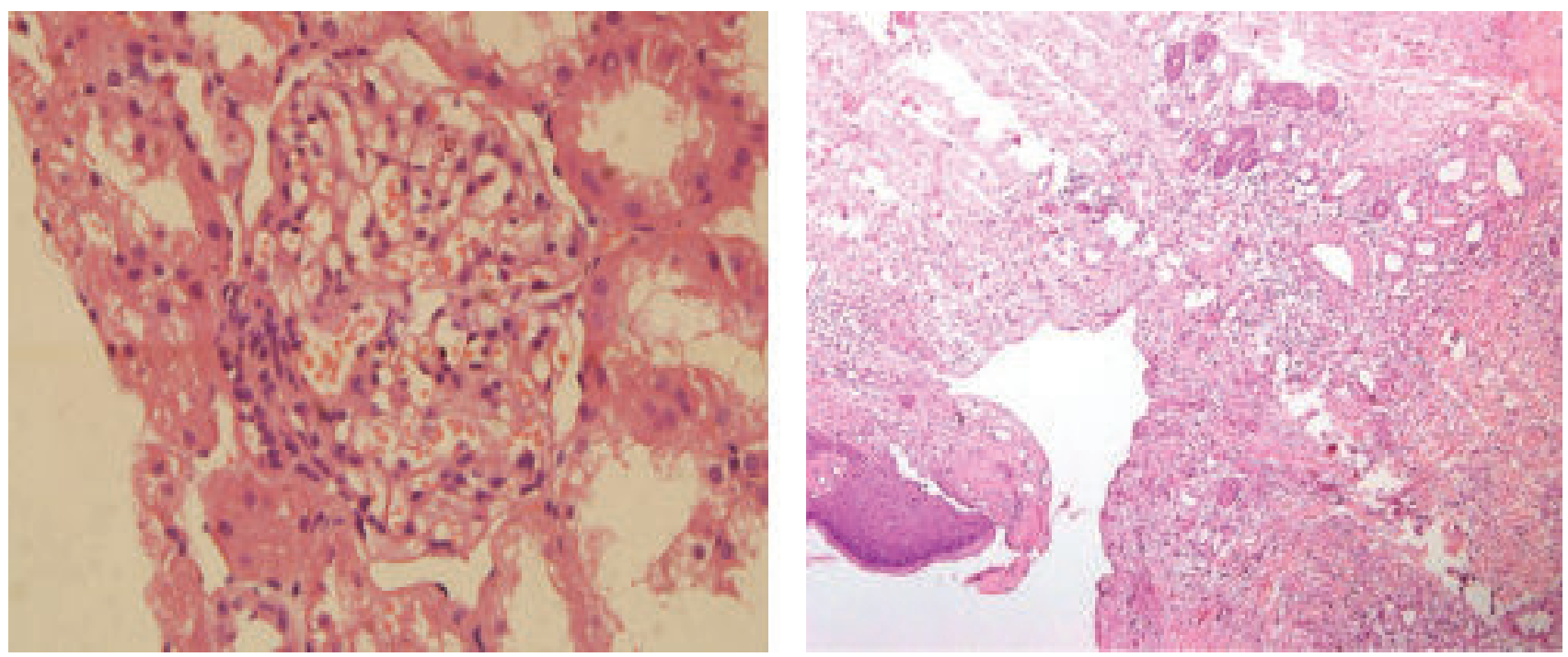

Figure-3 and 4: Renal biopsy showing crescent formation and Skin histo showing vasculitis 

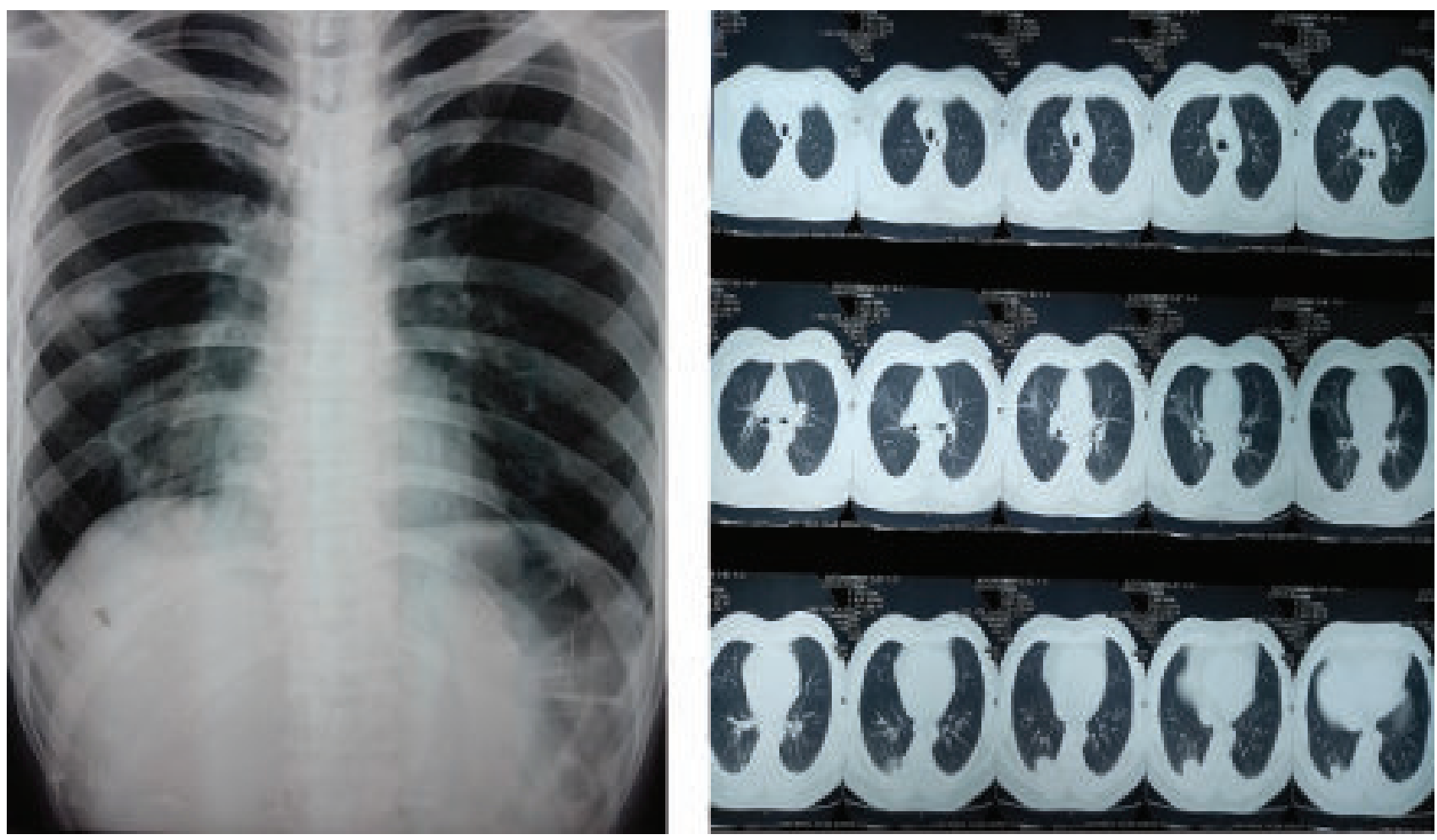

Fig.- 5 and 6: Cavitary lesions undergoing resolution and CT shows complete resolution

\section{Discussion:}

The differential diagnoses in this case were critically analysed before reaching the final clinical diagnosis and managing the patient.

Patient was initially managed in his local hospital as a case of pulmonary TB based on the finding of cavitary lesion in chest X-ray in the context of high prevalence of tuberculosis in Bangladesh. Tubercular cavitary lesions usually produce positive sputum smears or gene Xpert results which was not the case here. ${ }^{6}$ Besides, the cavitary lesion was not in the upper lobe of lung as is usual for post primary TB. ${ }^{7}$ Moreover, patient failed to improve and the cavity persisted after getting anti-TB for 3 months. Still, the possibility of drug resistant TB was excluded by repeating Gene Xpert of sputum which came negative.

It was tried to explain the entire clinical scenario by a single diagnosis of Rheumatoid arthritis with systemic complications like vasculitis and cavitating palmonary nodule. ${ }^{2}$ It may seem pertinent as patient was having RA for 10 years and never received any disease modifiying anti rheumatoid agent (DMARD). But there is no report of upper airway involvement by secondary vasculitis in RA. Besides, patient presented with nephritic rather than nephrotic syndrome which occurs in longstanding RA secondary to amyloidosis. But necrotising crescentic glomerulonephritis can occur in

\section{RA patients positive for pANCA, not cANCA. ${ }^{8}$}

Disseminated fungal infection like hiostoplasmosis was another much thought possibility as the patient had uncontrolled diabetes prior to this illness. Though the clinical features support it but objective evidences from sputum microscopy and culture for fungus were absent.

Considering all these points, the double pathology of Rheumatoid arthritis and Wegener's granulomatosis were made the final clinical diagnosis.

The chance of demonstration of granuloma is higher in lung biopsies than renal biopsies. ${ }^{3}$ But renal biopsy was opted instead of lung biopsy for technical convenience. It revealed pauci-immune crescentic glomerulonephritis but no granuloma. This finding is consistent with both microscopic ployangiitis and Wegener's. ${ }^{9}$ However, the former presents with renal symptoms and predominantly positive pANCA. The combined involvement of upper and lower (cavities) respiratory tracts, gastrointestinal system, skin, joints, kidneys (pauci-immune crescentic glomerulonephritis) and lately eye with high titres of cANCA can only be explained by GPA (Wegener's). ${ }^{3}$

Different literatures were searched to find out existence of any association between Rheumatoid arthritis and Granulomatosis with polyangiitis. Patients with rheumatoid arthritis are often positive for ANCAs. 
Among them those with positive pANCA were found to develop more severe disease in the form of rheumatoid vasculitis. A small number of RA patients had true ANCA associated vasculitis (AAV) and most of them had pANCA (anti myeloperoxidase antibody). ${ }^{10}$ Such case reports are only around 40 in number. ${ }^{11}$ Some papers observed the tendency to develop AAV in RA patients treated with anti-TNF á and D-penicillamine which was not the case in this patient. 12, 13 Furthermore, studies reported common susceptibility genes like 620W allele of the PTPN22 gene and certain alleles in major histocompatibilty complex as well as polymorphisms in the uteroglobin and NF-kappaB2 genes as possible explanation for coexistence of connective tissue disorders and ANCA associated vasculitis. $14,15,16$

Cyclophosphamide and methylprednisolone were administered to this patient as induction-remission therapy according to EULAR/ERA-EDTA 2016 recommendation statement $3 .{ }^{17}$ Pulse injectable cyclophosphamide was chosen considering the better side effect profile than daily oral doses due to lesser cumulation in the body. The pulse therapy is also proved to be better in achieving remission. ${ }^{18,19}$ But it is associated with higher rate of relapse as occurred in this case. ${ }^{20}$ Azathioprine was added during treating the relapse in accordance with EULAR recommendation. 17

\section{Conclusion:}

Any patient of Rheumatoid arthritis presenting with fulminant extra articular features should be thoroughly examined and investigated for coexisting second autoimmune disease like vasculitis. The latter should be addressed first while managing such patients as it is life threatening. Urgent administration of high dose intravenous immunosuppressants is the mainstay of treatment. Treatment should not be delayed for histopathological diagnosis if patient's condition does not permit it or facilities are not readily available.

\section{References:}

1. Clunie GPR, Ralston SH. Rheumatology and Bone Disease. In: Ralston SH, Penman ID, Strachan MWJ, Hobson RP, editors. Davidson's Principles and Practice of Medicine. 23rd edition. UK: Elsevier Ltd; 2018.p.1022.

2. Shah A, Clair EWS. Rheumatoid arthritis. In: Jameson JL, Fauci AS, Kasper DL, Hauser SL, Longo DL, Loscalzo $\mathrm{J}$, editors. Harrison's Principles of Internal Medicine. 20th ed. USA: The McGraw-Hill Companies, Inc.; 2018. p. 2531.

3. Langford CA, Fauci AS. The vasculitis Syndromes. In: Jameson JL, Fauci AS, Kasper DL, Hauser SL, Longo DL, Loscalzo J, editors. Harrison's Principles of Internal
Medicine. 20th ed. USA: The McGraw-Hill Companies, Inc.; 2018. p. 2574-2581.

4. Hoffman GS, Kerr GS, Leavitt RY, Hallahan CW, Lebovics RS, Travis WD, et al. Wegener granulomatosis: an analysis of 158 patients. Ann Intern Med. 1992 Mar 15;116(6):488-98. https:// doi.org/10.7326/00034819-116-6-488. PMid:1739240

5. Phillip R, Luqmani R. Mortality in systemic vasculitis: a systematic review. Clin Exp Rheumatol. SeptemberOctober 2008. 26:S94-S104.

6. Gomes M, Saad Júnior R, Stirbulov R. Pulmonary tuberculosis: relationship between sputum bacilloscopy and radiological lesions. Rev. Inst. Med. Trop. Sao Paulo. 2003; 45:275-281. https://doi.org/10.1590/S003646652003000500007 PMid:14743668

7. Reid PT, Innes JA. Respiratory Medicine. In: Ralston SH, Penman ID, Strachan MWJ, Hobson RP, editors. Davidson's Principles and Practice of Medicine. 23rd edition. UK: Elsevier Ltd; 2018.p.589.

8. A. Icardi, P. Araghi, M. Ciabattoni, U. Romano, P. Lazzarini, G. Bianchi. Kidney involvement in rheumatoid arthritis. Rheumatismo. Vol 55, No 2 (2003):76. https://doi.org/10.4081/reumatismo. 2003.76 PMid: 12874640

9. Jennette JC, Falk RJ. Renal and Systemic Vasculitis. In: Feehally J, Floege J, Tonelli M, Johnson RJ, editors. Comprehensive Clinical Nephrology. 6th edition. UK: Elsevier Inc; 2019.p.290-300.

10. Braun MG, Csernok E, Schimitt WH, Gross WL. Indicence, target antigens, and clinical implications of antineutrophil cytoplasmic antibodies in rheumatoid arthritis. J Rheumatol 1996; 23(5):826-830.

11. Martin-Nares E, Zuñiga-Tamayo D, Hinojosa-Azaola A. Prevalence of overlap of antineutrophil cytoplasmic antibody associated vasculitis with systemic autoimmune diseases: an unrecognised example of poliautoimmunity. Clinical Rheumatology 2019; 38:97106. https://doi.org/10.1007/s10067-018-4212-1 PMid:30006919

12. Ramos-Casals M, Brito-Zerón P, Muñoz S, Soria N, Galiana D, Bertolaccini L, et al. Autoimmune diseases induced by TNF-targeted therapies: analysis of 233 cases. Medicine (Baltimore) 2007; 86(4):242-251. https://doi.org/10.1097/MD.0b013e3181441a68 PMid:17632266

13. Bienaimé F, Clerbaux G, Plaisier E, Mougenot B, Ronco $\mathrm{P}$, Rougier JP. D-Penicillamine induced ANCAassociated crescentic glomerulonephritis in Wilson disease. Am J Kidney Dis 2007; 50(5):821-825. https:/ /doi.org/10.1053/j.ajkd.2007.05.026 PMid:17954295

14. Rincón JF, Cano DL, Morales SJ, Jiménez ML, Cobos RE, Bello JR et al. The functional PTPN22 C1858T polymorphism confers risk for rheumatoid arthritis in patients from Central Mexico. Clin Rheumatol 2016; 35(6): 1457-1462. https://doi.org/10.1007/s 10067 016-3223-z. PMid:26951256 
15. Zenteno JC, Correa-Gómez V, Pompa-Mera EN, Lima G, Pedroza-Seres M, Flores-Suárez LF. The PTPN22 R620W polymorphism in anti-neutrophil cytoplasmic antibody-associated vasculitis in Mexican Mestizos. Rheumatology (Oxford) 2016; 55(12):2271-2273. https://doi.org/10.1093/rheumatology/kew358 PMid:27686100

16. Menegatti E, Davit A, Francica S, Berardi D, Rossi D, Baldovino S, Tovo PA, Sena LM, Roccatello D. Genetic factors associated with rheumatoid arthritis and systemic vasculitis: evaluation of a panel of polymorphisms. Dis Markers 2009; 27(5):217-223. https://doi.org/10.1155/2009/435108 PMid: 20037209 PMCid:PMC3835025

17. Yates M, Watts RA, Bajema IM, Cid MC, Crestani B, Hauser T, et Al. EULAR/ERA-EDTA recommendations for the management of ANCA-associated vasculitis. Annals of the Rheumatic Diseases 2016;75:1583-1594. https://doi.org/10.1136/annrheumdis-2016eular.1168 https://doi.org/10.1136/annrheumdis2016-209133 PMid:27338776

18. De Groot K, Adu D, Savage COS. The value of pulse cyclophosphamide in ANCA-associated vasculitis: Metaanalysis and critical review. Nephrol Dial Transplant 2001; 16:2018-27. https://doi.org/10.1093/ndt/ 16.10.2018 PMid:11572891

19. De Groot K, Harper L, Jayne DR, et al. Pulse versus daily oral cyclophosphamide for induction of remission in antineutrophil cytoplasmic antibody-associated vasculitis: a randomized trial. Ann Intern Med 2009; 150:670-80. https://doi.org/10.7326/0003-4819-15010-200905190-00004 PMid:19451574

20. Harper L, Morgan MD, Walsh M, et al. Pulse versus daily oral cyclophosphamide for induction of remission in ANCA-associated vasculitis: long-term follow-up. Ann Rheum Dis 2012; 71:955-60. https://doi.org/10.1136/ annrheumdis-2011-200477 PMid:22128076. 